\title{
DESENVOLVIMENTO, PRODUTIVIDADE \\ E SOBREVIVÊNCIA DE MARACUJAZEIRO-AMARELO ENXERTADO E CULTIVADO EM ÁREA COM HISTÓRICO DE MORTE PREMATURA DE PLANTAS ${ }^{1}$
}

\author{
JOSÉ CARLOS CAVICHIOLI ${ }^{2}$, LUIZ DE SOUZA CORRÊA ${ }^{3}$, \\ MARIA JOSÉ DE MARCHI GARCIA ${ }^{4}$, IVAN HERMAN FISCHER ${ }^{4}$
}

RESUMO - O objetivo deste trabalho foi avaliar o desenvolvimento vegetativo, a produtividade e a sobrevivência do maracujazeiro-amarelo (Passiflora edulis Sims) enxertado sobre três porta-enxertos, em área com histórico de morte prematura de plantas. O experimento foi conduzido no município de AdamantinaSP, no período de maio de 2006 a fevereiro de 2007, adotando-se o delineamento de blocos ao acaso, com três tratamentos e sete repetições. Os porta-enxertos avaliados foram Passiflora edulis, P. alata e P. gibertii, utilizando-se da enxertia convencional por garfagem tipo fenda cheia. Avaliaram-se o diâmetro do caule do porta-enxerto e do enxerto, o comprimento do entrenó e dos ramos secundários, o número de ramos terciários e o de frutos, a massa média, o diâmetro e o comprimento médio dos frutos, a produtividade e a sobrevivência de plantas. Os resultados demonstraram que o uso da enxertia no maracujazeiro é uma opção viável como meio de propagação vegetativa, assim como forma de controle de alguns patógenos habitantes do solo, um dos problemas que têm limitado a expansão da cultura. As plantas enxertadas sobre $P$. edulis apresentaram melhor desenvolvimento inicial, seguido de $P$. gibertii e de $P$. alata. A menor produtividade ocorrreu em plantas sobre P. alata. Mesmo com a presença de Fusarium solani e Rotylenchulus reniformis nos solos, $91 \%$ das plantas enxertadas sobre $P$. gibertii sobreviveram após 12 meses de plantio no campo, enquanto em $P$. alata e $P$. edulis, esses índices foram de $60 \%$ e $8,6 \%$, respectivamente, mostrando assim a maior tolerância às doenças causadas por patógenos habitantes do solo por $P$. gibertii.

Termos para indexação: Passifloraceae, maracujá-amarelo, enxertia, frutificação, controle de doenças.

\section{GROWTH, YIELD AND SURVIVAL OF YELLOW PASSION FRUIT GRAFTED AND CULTIVED IN AREA WITH DESCRIPTION OF PREMATURE DEATH OF PLANTS}

\begin{abstract}
The objective of this study was to evaluate the vegetative growth, yield and survival of yellow passion fruit (Passiflora edulis Sims) grafted on the three rootstocks in area with description of premature death of plants. The experiment was carried out in Adamantina, SP, Brazil, from May 2006 to February 2007, adopting the statistical design of randomized blocks, with three treatments and seven replications. The rootstocks evaluated were Passiflora edulis, $P$. alata and $P$. gibertii, using conventional cleft grafting. The variables evaluated were: stem diameter of the rootstocks, stem diameter of the grafts, length of internodes, length of the secondary branches, number of tertiary branches, number of fruits, average weight of fruits, diameter and length of fruits, yield and plant survival. The work demonstrated that the use of the grafting in yellow passion fruit is a viable option as vegetative propagation, as well as a means of controlling some soil pathogens, one problem that has limited the expansion of culture. It was observed that plants grafted on $P$. edulis presented better initial vegetative growth, followed of $P$. gibertii and of $P$. alata. The lowest yield was obtained in P. alata. It was observed that although the presence of Fusarium solani and Rotylenchulus reniformis in soil, $91 \%$ of the plants grafted on $P$. gibertii survival after 12 months of field planting, whereas in $P$. alata and $P$. edulis these indices were $60 \%$ and $8.6 \%$, respectively, showing a bigger tolerance to the root diseases.
\end{abstract}

Index terms: Passifloraceae, yellow passion fruit, graft, fructification, control of diseases.

\footnotetext{
1(Trabalho 126-10). Recebido em: 13-05-2010. Aceito para publicação EM: 29-09-2010. Parte da tese de doutorado do primeiro autor apresentado à Faculdade de Engenharia de Ilha Solteira/UNESP.

${ }^{2}$ Pesquisador da Polo da Alta Paulista/APTA, C. P. 191, 17.800-000, Adamantina -SP, E-mail: jccavichioli@apta.sp.gov.br

${ }^{3}$ Professor Titular do Depto. de Fitotecnia, Tecnologia de Alimentos e Socioeconomia da FEIS-UNESP, Ilha Solteira, E-mail: lcorrea@agr.feis.unesp.br

${ }^{4}$ Pesquisadores da APTA Regional Bauru, E-mails: mjdemarchi@apta.sp.gov.br, ihfische@apta.sp.gov.br
} 


\section{INTRODUÇÃO}

A morte prematura de plantas, doença que está associada a fungos habitantes do solo, como Fusarium oxysporum Schl f. sp. passiflorae, F. solani (Mart.) Sacc. e Phytophthora cinnamomi Rands e à bactéria Xanthomonas axonopodis pv. passiflorae (Pereira) Dye, constitui-se em um sério problema para a cultura do maracujazeiro-amarelo (Passiflora edulis Sims) (CHAVES et al., 2004; FISCHER et al., 2005; CAVICHIOLI et al., 2009b), responsável pela redução de área plantada e pelo caráter itinerante da cultura.

No Estado de São Paulo, aproximadamente um terço da área plantada com maracujazeiro encontra-se na região oeste (INSTITUTO DE ECONOMIA AGRÍCOLA - IEA, 2008), que tem sofrido com diversas doenças, entre as quais, a morte prematura das plantas, comprometendo severamente a produção e determinando a migração para outras regiões do Estado.

A planta tem seu sistema radicular afetado com a penetração do patógeno, progredindo para o apodrecimento da região do colo e, consequentemente, o anelamento do caule pela destruição da casca e de vasos liberianos. A translocação da seiva é interrompida, causando a murcha e repentina morte das plantas, cujas folhas e frutos ficam retidos (SÃO JOSÉ, 1997).

Pelo fato de ser uma doença vascular, não há controle químico, devendo utilizar-se de medidas preventivas para o seu controle, tais como: evitar o plantio em solos pesados e compactados, utilizar mudas sadias e evitar ferimentos no colo e nas raízes das plantas. O uso da enxertia no maracujazeiro é uma técnica descrita por diversos autores (CHAVES et al., 2004; SILVA et al., 2005; CAVICHIOLI et al., 2009b). A utilização de porta-enxertos tolerantes à morte prematura de plantas pode ser uma forma de viabilizar o plantio de maracujazeiros em áreas com histórico da doença (YAMASHIRO; LANDGRAF ,1979; BRAGA et al., 2006).

Yamashiro e Landgraf (1979) constataram que $P$. alata Curtis é um porta-enxerto compatível para o maracujazeiro-amarelo e também resistente à fusariose, além de induzir a precocidade de produção, sem alterar as qualidades tecnológicas do suco. Por outro lado, alguns autores também verificaram que $P$. gibertii N.E. Brown apresentou resistência à morte prematura de plantas (OLIVEIRA et al., 1984; RONCATTO et al., 2004), apesar de apresentar produtividade e vigor de plantas inferior a outros porta-enxertos (STENZEL; CARVALHO, 1992). São José et al. (2000) testaram diversas espécies de maracujazeiros e verificaram que $P$. alata e $P$. gibertii apresentavam melhor comportamento em relação à morte prematura. Cavichioli et al. (2009a), avaliando seis espécies de maracujazeiro em área com histórico de morte prematura, relatam a sobrevivência de $100 \%$ de plantas de $P$. gibertii e de $P$. setaceae e de $93 \%$ de P. alata, aos 270 dias do plantio.

O objetivo do presente trabalho foi avaliar o comportamento de três espécies de maracujazeiro como porta-enxertos para o maracujazeiro-amarelo em área com histórico de morte prematura de plantas.

\section{MATERIAL E MÉTODOS}

O experimento foi instalado no município de Adamantina-SP, na região da Nova Alta Paulista e conduzido em uma área com histórico de morte prematura de plantas ( $100 \%$ de incidência), localizada a $413 \mathrm{~m}$ de altitude, $21^{\circ} 39^{\prime} \mathrm{S}$ de latitude e $51^{\circ} 05^{\prime} \mathrm{W}$ de longitude, no período de maio de 2006 a fevereiro de 2007. O solo da área experimental foi classificado como Argissolo Vermelho-Amarelo, eutrófico, A moderado, textura arenosa/média e topografia ondulada (EMBRAPA, 2006).

O clima da região é Cwa, segundo a classificação de Köeppen, com estação chuvosa no verão e seca no inverno (CEPAGRI, 2009). A precipitação média anual é de $1.300 \mathrm{~mm}$. A temperatura média anual está em torno de $22-23^{\circ} \mathrm{C}$; a do mês mais quente é em torno de $26^{\circ} \mathrm{C}$; a do mês mais frio está por volta de $17-18^{\circ} \mathrm{C}$.

As sementes de maracujazeiro-amarelo seleção Sul Brasil foram procedentes de pomar do município de Adamantina, e as sementes das espécies $P$. gibertii e $P$. alata foram procedentes do Departamento de Produção Vegetal da Faculdade de Ciências Agrárias e Veterinárias de Jaboticabal - UNESP.

Os porta-enxertos $P$. edulis, $P$. gibertii e $P$. alata, assim como as plântulas de maracujazeiroamarelo para fornecimento dos garfos, foram produzidos em casa de vegetação, por meio de semeadura direta em tubetes de $19 \mathrm{~cm}$ x 5,5 cm. A enxertia foi realizada 25 dias após a emergência da plantas, quando os porta-enxertos atingiram cerca de 6 a $8 \mathrm{~cm}$ de altura e uma das folhas definitivas, utilizando-se do método de garfagem em fenda cheia.

De acordo com o resultado da análise de solo realizada antes do plantio (Tabela 1), foram efetuadas as recomendações de adubação e calagem para a cultura, seguindo Piza Júnior et al. (1996). Foram abertas covas de 40 x 40 x $40 \mathrm{~cm}$ e adubadas com 20 litros de esterco de curral curtido, $600 \mathrm{~g}$ de superfosfato simples, $200 \mathrm{~g}$ de calcário dolomítico e $50 \mathrm{~g}$ de FTE. 
O processo de condução foi espaldeira com um fio de arame liso, fixo em mourões de $2 \mathrm{~m}$ de altura, espaçados de $9 \mathrm{~m}$, intercalados com um bambu. As plantas foram conduzidas com um único ramo vegetativo (ramo primário) até atingir o fio de arame, sendo que as brotações laterais foram eliminadas. Ao atingir o arame, o ramo foi cortado no ápice, deixando crescer um ramo para cada lado da espaldeira (ramo secundário). Os ramos que saíram desses foram chamados de ramos terciários e não foram desbrotados. $\mathrm{O}$ espaçamento da cultura foi de $3 \mathrm{~m}$ entre plantas, por 2,5 m entre ruas.

As pulverizações foram realizadas sempre no período da manhã para não afetar os insetos polinizadores. Para as lagartas, percevejos e besouros, foram utilizados inseticidas organofosforados. Para o controle de doenças fúngicas, foram efetuados tratamentos preventivos, utilizando-se da mistura de oxicloreto de cobre e mancozeb. Foi necessária uma pulverização curativa para antracnose, com o fungicida carbendazim.

A polinização artificial foi realizada manualmente, entre 14 e 17 horas, sempre que havia flores abertas.

O controle das ervas daninhas foi realizado por capina manual na linha, e as entrelinhas foram mantidas vegetadas com gramíneas, sendo roçadas sempre que necessário.

As adubações de formação e produção foram realizadas após o pegamento das mudas, obedecendo à recomendação de Piza Júnior et al. (1996), que correspondeu, na fase de formação, a $30 \mathrm{~g}$ de nitrato de amônio aos 30 dias, $45 \mathrm{~g}$ de nitrato de amônio aos 60 dias, $100 \mathrm{~g}$ da fórmula 20-05-20 aos 90 dias e 150 $\mathrm{g}$ da fórmula 20-05-20 aos 120 dias após o plantio. $\mathrm{Na}$ adubação de produção, foram utilizados 100 $\mathrm{kg} / \mathrm{ha}$ de $\mathrm{N}, 100 \mathrm{~kg} / \mathrm{ha}$ de $\mathrm{P}_{2} \mathrm{O}_{5}$ e $200 \mathrm{~kg} / \mathrm{ha}$ de $\mathrm{K}_{2} \mathrm{O}$ parcelados em oito vezes, no período de outubro de 2006 a fevereiro de 2007.

Avaliaram-se, nas plantas de maracujazeiroamarelo enxertadas em $P$. edulis, $P$. gibertii e $P$. alata, os seguintes parâmetros: diâmetro do caule do porta-enxerto, diâmetro do caule do enxerto, comprimento do entrenó e dos ramos secundários, número de ramos terciários (verticais), número de frutos/planta, produtividade, massa média de frutos, diâmetro e comprimento médio dos frutos e sobrevivência de plantas. As avaliações foram realizadas mensalmente, sendo que amostras de raízes de plantas mortas foram enviadas para análises nos laboratórios da UNESP de Ilha Solteira e da Unidade de Pesquisa e Desenvolvimento da Apta de Bauru, para constatar a presença de $F$. solani e do nematoide $R$. reniformis.

A partir de fevereiro de 2007, no tratamento com $P$. edulis, não havia número de plantas suficientes para as avaliações devido à morte prematura de plantas.

Adotou-se o delineamento experimental em blocos ao acaso, com três tratamentos, sete repetições e cinco plantas por parcela.

\section{RESULTADOS E DISCUSSÃO}

Não houve diferenças significativas entre as espécies estudadas como porta-enxertos para diâmetro do caule, aos 270 dias do plantio no campo (Tabela 2). Até os sessenta dias, o $P$. alata foi inferior aos demais tratamentos, mas, a partir dos noventa dias, foi semelhante ao P. edulis. O P. gibertii apresentou menor diâmetro aos 90 dias, em relação ao $P$. edulis, e aos 180 dias, em relação ao $P$. edulis e P. alata, mostrando que o $P$. alata possui desenvolvimento inicial mais lento, comparado com as outras espécies, mas o desenvolvimento é compensado com a idade da planta. O P. gibertii mostrou comportamento inverso, com bom desenvolvimento inicial, que foi reduzido na fase intermediária da cultura, apesar de não ter apresentado diferença no estádio final, provavelmente em razão da ocorrência de $F$. solani, em $P$. edulis e $P$. alata, e do nematoide $R$. reniformis em P. alata. Estudos realizados por Klein et al. (1984) demonstraram elevada suscetibilidade de P. alata a nematoides formadores de galhas, enquanto $P$. edulis f. flavicarpa mostrou alta resistência ao parasito.

O diâmetro do caule das plantas de maracujazeiro-amarelo, medido a $12 \mathrm{~cm}$ do colo, enxertadas sobre $P$. edulis, não diferiu de $P$. gibertii até os 90 dias, e foi superior aos demais tratamentos aos 180 e 270 dias de plantio no campo (Tabela 2). Plantas enxertadas sobre $P$. alata sempre tiveram menor desenvolvimento. Observa-se que, apesar de o diâmetro dos maracujazeiros utilizados como portaenxertos não terem diferido entre si aos 270 dias, eles interferiram no diâmetro do caule do enxerto, com destaque para as plantas enxertadas sobre P. edulis, indicando assim maior compatibilidade entre plantas da mesma espécie.

Plantas enxertadas sobre $P$. alata apresentaram valores inferiores de comprimentos de entrenós e de ramos secundários, e número de ramos terciários que as enxertadas nos outros dois porta-enxertos (Tabela 3), resultando em menor crescimento do maracujazeiro-amarelo.

Os maiores comprimentos de ramos secundários e número de ramos terciários, aos 150 dias, ocorreram nas plantas enxertadas sobre $P$. edulis (Tabela 3), evidenciando assim o melhor desenvol- 
vimento destas plantas até esse período.

Analisando as variáveis diâmetro do caule do enxerto, comprimentos do entrenó de ramos secundários e número de ramos terciários (Tabelas 2 e 3), constata-se que as plantas enxertadas sobre $P$. edulis apresentam melhor desenvolvimento, enquanto as plantas enxertadas sobre $P$. alata, tiveram o pior desempenho. O melhor desempenho apresentado pelo $P$. edulis já era esperado, por tratar-se de plantas da mesma espécie, havendo, assim, maior compatibilidade entre os mesmos, de acordo com o relato de Nogueira Filho (2003). O menor desenvolvimento apresentado pelas plantas enxertadas sobre $P$. alata deve estar relacionado à ocorrência do nematoide $R$. reniformis, identificado em análises efetuadas em raízes das plantas mortas.

O tratamento com $P$. alata apresentou número de frutos muito inferior em relação aos demais tratamentos, durante os meses de avaliação (Tabela 4). Provavelmente porque esse material sempre apresentou menor desenvolvimento (Tabelas 2 e 3 ). Em $P$. edulis, o número de frutos foi reduzindo com o passar dos meses, resultado da morte de plantas por $F$. solani, enquanto em $P$. gibertii se observou o inverso, ou seja, o número de frutos foi crescente com o passar dos meses, inclusive superior a $P$. edulis, em fevereiro, uma vez que esta espécie se mostrou mais resistente ao fungo habitante do solo. Entretanto, ao analisar o total acumulado nos três meses de avaliação, observa-se que não houve diferenças estatísticas para o número de frutos entre estas duas espécies.

As maiores produtividades foram obtidas com $P$. edulis e $P$. gibertii, superiores à $P$. alata (Tabela 4). Assim como para número de frutos, verificou-se aumento na produtividade das plantas enxertadas sobre $P$. gibertii, enquanto no tratamento com $P$. edulis, ocorreu o inverso, uma redução com a idade da cultura. Isso se explica em razão da ocorrência da morte prematura, constatada a partir de dezembro, o que afetou mais seriamente essas plantas. Nota-se que, apesar da maior resistência das plantas de $P$. gibertii ao $F$. solani, comprovada pela alta sobrevivência desse material, a produtividade no período analisado não foi diferente com relação ao $P$. edulis, provavelmente porque a maior compatibilidade verificada nesse material compensou as perdas ocorridas com a morte das plantas.

A massa média dos frutos não variou entre os porta-enxertos, o que também foi observado por Stenzel e Carvalho (1992), o mesmo acontecendo com o diâmetro dos frutos (Tabela 5). Frutos de plantas enxertadas sobre $P$. alata tiveram um comprimento superior aos enxertados sobre $P$. gibertii, e não diferiram do $P$. edulis. Oliveira et al. (1984) não detectaram diferenças quanto ao tamanho dos frutos em plantas enxertadas sobre $P$. gibertii e $P$. edulis.

A maior sobrevivência no campo ocorreu com as plantas enxertadas sobre $P$. gibertii (91\%), seguida de $P$. alata $(60 \%)$ (Tabela 6). As primeiras mortes foram registradas oito meses após o plantio das mudas no campo (dezembro), em plantas enxertadas sobre $P$. edulis. A maior porcentagem de mortes em $P$. edulis ocorreu no período de dezembro a janeiro, reduzindo para $34,3 \%$ o número de plantas sobreviventes. É importante ressaltar que, neste período, registrouse alto índice de precipitação pluviométrica e altas temperaturas (Figura 1), condições que favoreceram o desenvolvimento do fungo (SÃO JOSÉ, 1997). Também em janeiro se observaram as primeiras mortes no porta-enxerto $P$. alata, reduzindo para $85,7 \%$ o número de plantas sobreviventes.

Os resultados das análises indicaram a ocorrência de $F$. solani e do nematoide $R$. reniformis. Nas plantas enxertadas sobre $P$. gibertii, só ocorreu morte em fevereiro, ou seja, dez meses após o plantio no campo e, mesmo assim, em apenas 2,9\% das plantas. Apenas 8,6\% das plantas enxertadas sobre $P$. edulis sobreviveram após 12 meses de plantio da cultura. Segundo Roncatto et al. (2004), mesmo na ausência de fitonematoides, $F$. solani pode destruir $100 \%$ de plantas de maracujá-amarelo já no segundo ano de plantio.

Quando se utilizou o $P$. alata como portaenxerto, $60 \%$ das plantas sobreviveram. As mortes em $P$. alata, possivelmente, devem-se à interação entre $R$. reniformis e $F$. solani. Em Brunei, $R$. reniformis foi considerado o agente de predisposição à morte prematura do maracujazeiro, causada por Phytophthora spp. (PERREGRINE; YUNTON, 1980). Em P. gibertii, ocorreu o melhor comportamento em relação às doenças causadas por patógenos habitantes de solo, com $91,4 \%$ de plantas sobreviventes. Estes resultados estão de acordo com Oliveira et al. (1984), quando obtiveram $93,4 \%$ de sobrevivência para a combinação $P$. gibertii/P. edulis e $4 \%$ para pé-franco. Roncatto et al. (2004) registram 100\% de sobrevivência em plantas de $P$. gibertii em área com histórico de morte prematura. 
TABELA 1 - Resultados da análise química do solo da área experimental. Adamantina-SP, 2006.

\begin{tabular}{ccccccccccc}
\hline $\begin{array}{c}\mathrm{pH} \\
\mathrm{CaCl}_{2}\end{array}$ & $\begin{array}{c}\mathrm{M} . \mathrm{O} . \\
\mathrm{g} / \mathrm{dm}^{3}\end{array}$ & $\begin{array}{c}\mathrm{P} \\
\mathrm{mg} / \mathrm{dm}^{3}\end{array}$ & $\mathrm{~K}$ & $\mathrm{Ca}$ & $\begin{array}{c}\mathrm{Mg} \\
\mathrm{Al}\end{array} \begin{array}{c}\mathrm{H}+\mathrm{Al} \\
\mathrm{mmol}_{\mathrm{c}} / \mathrm{dm}^{3}\end{array}$ & $\mathrm{SB}$ & $\mathrm{CTC}$ & $\begin{array}{c}\mathrm{V} \\
\%\end{array}$ \\
\hline 4,9 & 10 & 18 & 2,6 & 22 & 6 & 0 & 20 & 30,6 & 50,6 & 60 \\
\hline
\end{tabular}

TABELA 2 - Diâmetro $(\mathrm{mm})$ do caule dos porta-enxertos e do enxerto medidos a $1 \mathrm{~cm}$ e a $12 \mathrm{~cm}$, respectivamente, do colo de plantas de maracujazeiro-amarelo enxertadas, medidas no dia do plantio (0) e 30; 60; 90; 180 e 270 dias após o plantio. Adamantina-SP, 2006 -2007.

\begin{tabular}{|c|c|c|c|c|c|c|}
\hline Porta-enxertos & 0 dia & 30 dias & 60 dias & 90 dias & 180 dias & 270 dias \\
\hline & \multicolumn{6}{|c|}{ Diâmetro do caule dos porta-enxertos } \\
\hline P. edulis & $4,26 \mathrm{a}$ & $4,88 \mathrm{a}$ & $6,23 \mathrm{a}$ & $7,74 \mathrm{a}$ & $16,35 \mathrm{a}$ & $20,12 \mathrm{a}$ \\
\hline P. alata & $3,11 \mathrm{~b}$ & $3,88 \mathrm{~b}$ & $4,85 \mathrm{~b}$ & $7,29 \mathrm{ab}$ & $15,14 \mathrm{a}$ & $18,96 \mathrm{a}$ \\
\hline P. gibertii & $4,49 \mathrm{a}$ & $4,90 \mathrm{a}$ & $5,69 \mathrm{a}$ & $6,59 \mathrm{~b}$ & $12,69 \mathrm{~b}$ & $17,60 \mathrm{a}$ \\
\hline $\mathrm{CV}(\%)$ & 8,45 & 7,98 & 7,04 & 7,45 & 8,48 & 10,59 \\
\hline & \multicolumn{6}{|c|}{ Diâmetro do caule do enxerto } \\
\hline P. edulis & $4,18 \mathrm{a}$ & $4,74 \mathrm{a}$ & $5,87 \mathrm{a}$ & $7,11 \mathrm{a}$ & $14,08 \mathrm{a}$ & $17,50 \mathrm{a}$ \\
\hline P. alata & $3,13 \mathrm{~b}$ & $3,61 \mathrm{~b}$ & $4,16 \mathrm{~b}$ & $5,55 \mathrm{~b}$ & $10,85 \mathrm{~b}$ & $13,28 \mathrm{~b}$ \\
\hline P. gibertii & $3,99 \mathrm{a}$ & $4,42 \mathrm{a}$ & $5,49 \mathrm{a}$ & $6,43 \mathrm{a}$ & $11,27 \mathrm{~b}$ & $14,92 \mathrm{~b}$ \\
\hline CV $(\%)$ & 4,44 & 6,01 & 7,43 & 7,92 & 10,97 & 11,07 \\
\hline
\end{tabular}

Médias seguidas de letras distintas na coluna diferem entre si, significativamente, ao nível de 5\% de probabilidade, pelo teste de Tukey.

TABELA 3 - Comprimento médio de entrenó $(\mathrm{cm})$ e de ramos secundários $(\mathrm{cm})$ e número de ramos terciários de plantas de maracujazeiro-amarelo enxertadas sobre três porta-enxertos, aos 150 dias após o plantio. Adamantina-SP, 2006-2007.

\begin{tabular}{cccc}
\hline Porta-enxertos & $\begin{array}{c}\text { Comprimento } \\
\text { de entrenó }\end{array}$ & $\begin{array}{c}\text { Comprimento dos } \\
\text { ramos secundários }\end{array}$ & Ramos terciários \\
\hline P. edulis & $6,64 \mathrm{a}$ & $218,09 \mathrm{a}$ & $14,57 \mathrm{a}$ \\
P. alata & $5,73 \mathrm{~b}$ & $72,87 \mathrm{c}$ & $2,24 \mathrm{c}$ \\
P. gibertii & $6,63 \mathrm{a}$ & $166,56 \mathrm{~b}$ & $9,41 \mathrm{~b}$ \\
\hline CV $(\%)$ & 7,22 & 20,73 & 33,59 \\
\hline
\end{tabular}

Médias seguidas de letras distintas diferem entre si, significativamente, ao nível de 5\% de probabilidade, pelo teste de Tukey.

TABELA 4 - Número médio de frutos por planta e produtividade $(\mathrm{kg} / \mathrm{ha})$ de maracujazeiro-amarelo enxertado sobre três porta-enxertos, no período de dezembro de 2006 a fevereiro de 2007. Adamantina-SP.

\begin{tabular}{|c|c|c|c|c|c|c|c|c|}
\hline \multirow[t]{3}{*}{$\begin{array}{l}\begin{array}{l}\text { Porta- } \\
\text { enxertos }\end{array} \\
\end{array}$} & \multicolumn{2}{|c|}{ Dezembro/06 } & \multicolumn{2}{|c|}{ Janeiro/07 } & \multicolumn{2}{|c|}{ Feveveiro/07 } & \multicolumn{2}{|r|}{ Total } \\
\hline & Número & & Número & & Número & & Número & \\
\hline & $\begin{array}{c}\text { de } \\
\text { frutos }\end{array}$ & Produtividade & $\begin{array}{c}\mathrm{de} \\
\text { frutos }\end{array}$ & Produtividade & $\begin{array}{c}\mathrm{de} \\
\text { frutos }\end{array}$ & Pro & $\begin{array}{c}\text { de } \\
\text { frutos }\end{array}$ & Produ \\
\hline P. edulis & $7,14 \mathrm{a}$ & $1.757,0 \mathrm{a}$ & $6,86 \mathrm{a}$ & $1.760,0 \mathrm{a}$ & $2,81 \mathrm{~b}$ & $720,0 \mathrm{~b}$ & $16,81 \mathrm{a}$ & $4.240,0 \mathrm{a}$ \\
\hline P. alata & $0,10 \mathrm{~b}$ & $20,0 \mathrm{~b}$ & $1,76 \mathrm{~b}$ & $480,0 \mathrm{~b}$ & $0,81 \mathrm{~b}$ & $121,0 \mathrm{~b}$ & $2,67 \mathrm{~b}$ & $625,0 \mathrm{~b}$ \\
\hline P. gibertii & $2,76 \mathrm{ab}$ & $594,0 \mathrm{ab}$ & $3,33 \mathrm{ab}$ & $824,0 \mathrm{ab}$ & $8,14 \mathrm{a}$ & $2.094,0 \mathrm{a}$ & $14,24 \mathrm{a}$ & $3.517,0 \mathrm{a}$ \\
\hline CV $(\%)$ & 100,55 & 109,32 & 73,71 & 68,34 & 67,10 & 66,64 & 58,36 & 59,75 \\
\hline
\end{tabular}

Médias seguidas de letras distintas na coluna diferem entre si, significativamente, ao nível de $5 \%$ de probabilidade, pelo teste de Tukey. 
TABELA 5 - Massa média $(\mathrm{g})$, comprimento $(\mathrm{cm})$ e diâmetro médio $(\mathrm{cm})$ de fruto de maracujazeiro-amarelo enxertado sobre três porta-enxertos. Adamantina-SP, 2007.

\begin{tabular}{lccc}
\hline Porta-enxertos & Massa de fruto & Comprimento de fruto & Diâmetro de fruto \\
\hline P. edulis & $185,46 \mathrm{a}$ & $9,46 \mathrm{ab}$ & $7,71 \mathrm{a}$ \\
P. alata & $190,13 \mathrm{a}$ & $9,67 \mathrm{a}$ & $7,72 \mathrm{a}$ \\
P. gibertii & $182,06 \mathrm{a}$ & $8,90 \mathrm{~b}$ & $7,49 \mathrm{a}$ \\
\hline CV $(\%)$ & 11,94 & 4,46 & 5,73 \\
\hline
\end{tabular}

Médias seguidas de letras distintas diferem entre si, significativamente, ao nível de $5 \%$ de probabilidade, pelo teste de Tukey.

TABELA 6 - Sobrevivência (\%) de plantas de maracujazeiro-amarelo enxertadas sobre três porta-enxertos, após onze meses de plantio. Adamantina-SP, 2007.

\begin{tabular}{lrrrrr}
\hline \multicolumn{1}{c}{ Porta-enxertos } & $\mathrm{Dez} / 06$ & $\mathrm{Jan} / 07$ & $\mathrm{Fev} / 07$ & $\mathrm{Mar} / 07$ & $\mathrm{Abr}$ \\
\hline P. edulis & $91,5 \mathrm{a}$ & $34,3 \mathrm{~b}$ & $20,0 \mathrm{c}$ & $8,6 \mathrm{c}$ & $8,6 \mathrm{c}$ \\
P. alata & $100,0 \mathrm{a}$ & $85,7 \mathrm{a}$ & $68,6 \mathrm{~b}$ & $65,7 \mathrm{~b}$ & $60,0 \mathrm{~b}$ \\
P. gibertii & $100,0 \mathrm{a}$ & $100,0 \mathrm{a}$ & $97,1 \mathrm{a}$ & $97,1 \mathrm{a}$ & $91,4 \mathrm{a}$ \\
\hline $\mathrm{CV}(\%)$ & 9,35 & 26,73 & 25,42 & 28,75 & 36,60 \\
\hline
\end{tabular}

Médias seguidas de letras distintas na coluna diferem entre si, significativamente, ao nível de 5\% de probabilidade, pelo teste de Tukey.
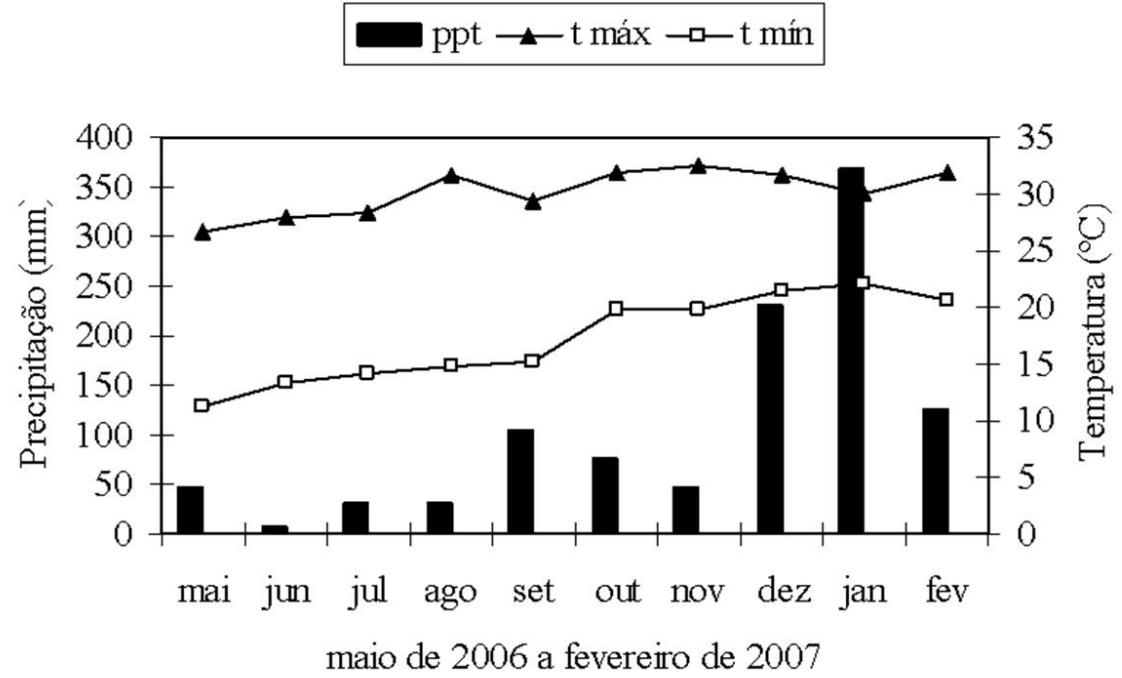

FIGURA 1 - Médias mensais de precipitação pluvial (ppt) e temperatura do ar, máxima (t máx.) e mínima (t mín.), no período de maio de 2006 a fevereiro de 2007. Adamantina-SP. 


\section{CONCLUSÕES}

1-Plantas enxertadas sobre $P$. edulis apresentaram melhor desenvolvimento inicial, enquanto as plantas enxertadas sobre $P$. alata tiveram o pior desempenho.

2-O maior número de frutos e as maiores produtividades foram obtidos sobre $P$. edulis e $P$. gibertii.

3-A maior tolerância às doenças causadas por patógenos habitantes do solo foi observada em plantas enxertadas sobre $P$. gibertii, com $91,43 \%$ de sobrevivência no campo, enquanto $P$. alata apresentou $60 \%$ de plantas sobreviventes, e P. edulis, $8,57 \%$.

\section{REFERÊNCIAS}

BRAGA, M.F.; SANTOS, E.C.; JUNQUEIRA, N.T.V.; SOUSA, A.A.T.C.; FALEIRO, F.G.; REZENDE, L.N.; JUNQUEIRA, K.P. Enraizamento de estacas de três espécies silvestres de Passiflora. Revista Brasileira de Fruticultura, Jaboticabal, v.28, n.2, p.284-288, 2006.

CAVICHIOLI, J.C.; CORREA, L. de S.; BOLIANI, A.C. Sobrevivência e desenvolvimento de seis espécies de maracujazeiros em área com histórico de morte prematura de plantas. Cultura Agronômica, Ilha Solteira, v. 18, n.04, p.67-73, 2009a.

CAVICHIOLI, J.C.; CORRÊA, L. de S.; BOLIANI, A.C.; OLIVEIRA, J.C. de. Uso de câmara úmida em enxertia hipocotiledonar de maracujazeiro-amarelo sobre três porta-enxertos. Revista Brasileira de Fruticultura, Jaboticabal, v.31, n.2, p.532-538, 2009 b.

CEPAGRI - Clima dos municípios paulistas. Disponível em: $<$ http://www.cpa.unicamp.br/outrasinformações/clima-dos-municípios-paulista.html>. Acesso em: 4 out. 2009.

CHAVES, R.C.; JUNQUEIRA, N.T.V.; MANICA, I.; PEIXOTO, J.R.; PEREIRA, A.V.; FIALHO, J.F. Enxertia de maracujazeiro-azedo em estacas herbáceas enraizadas de espécies de passifloras nativas. Revista Brasileira de Fruticultura, Jaboticabal, v.26, n.1, p.120-123, 2004.

EMBRAPA. Centro Nacional de Pesquisa de Solo. Sistema brasileiro de classificação de solos. 2.ed. Rio de Janeiro, 2006. 306p.
FISCHER, I.H.; LOURENÇO, S.A.; MARTINS, M.C.; KIMATI, H.; AMORIM, L. Seleção de plantas resistentes e de fungicidas para o controle da podridão do colo do maracujazeiro causada por Nectria haematococca. Fitopatologia Brasileira, Brasília, v.30, n.3, p.250-259, 2005.

INSTITUTO DE ECONOMIA AGRÍCOLA - IEA. Levantamento subjetivo do Estado de São Paulo. Maracujá: área e produção. Disponível em: $<w w w$. iea.sp.gov.br>. Acesso em: 10 fev. 2010

KLEIN, A.L.; FERRAZ, L.C.C.B.; OLIVEIRA, J.C. de. Comportamento de diferentes maracujazeiros em relação ao nematoide formador de galhas. Pesquisa Agropecuária Brasileira, Brasília, v.19, n. 2, p.207209, 1984.

NOGUEIRA FILHO, G.C. Enxertia hipocotiledonar de maracujazeiro-amarelo em diferentes espécies de passifloras silvestres. 2003. 119 f. Tese (doutorado em Agronomia) - Faculdade de Ciências Agrárias e Veterinárias, Universidade Estadual Paulista, Jaboticabal, 2003.

OLIVEIRA, J.C.; RUGGIERO, C.; NAKAMURA, K.; BAPTISTA, M. Comportamento de Passiflora edulis enxertada sobre $P$. gibertii N.E. Brown. In: CONGRESSO BRASILEIRO DE FRUTICULTURA, 7., 1983, Florianópolis. Anais... Florianópolis: EMPASC/SBF, 1984. v.3. p.989-993.

PERREGRINE, W.T.H.; YUNTON, B.A. A preliminary note on nematode pests in Brunei. Tropical Pest Management, London, v.26, 416-419, 1980.

PIZA JUNIOR, C. de T.; QUAGGIO, J.A.; MELETTI, L.M.M.; SILVA, J.R da; SÃO JOSÉ, A.R.; KAVATI, R. Maracujá. In: RAIJ, B. Van; CANTARELLA, H.; QUAGGIO, J.A.; FURLANI, A.M.C. Recomendações de adubação e calagem para o Estado de São Paulo. 2.ed. Campinas: Instituto Agronômico, 1996. 285p. (Boletim Técnico, 100).

RONCATTO, G.; OLIVEIRA, J.C. de; NOGUEIRA FILHO, G.C.; CENTURION, M.A.P.da C.; FERREIRA, F.R. Comportamento de maracujazeiros (Passiflora spp.) quanto à morte prematura. Revista Brasileira de Fruticultura, Jaboticabal, v.26, n.3, p.552-554, 2004. 
SÃO JOSÉ, A.R. Morte prematura do maracujazeiro. In: MANICA, I. Maracujá: temas selecionados. Porto Alegre: Cinco Continentes, 1997. p.47-57.

SÃO JOSÉ, A.R.; SANTOS, A.; SILVA, A.C. da; BONFIM, M.P.; MORAIS, O.M.; ATAIIDE, E.M.; BARBOSA, N.M.L. Fusariose no semiárido. In: CONGRESSO BRASILEIRO DE FRUTICULTURA, 16., 2000. Anais... p.470.

SILVA, F.M.; CORRÊA, L.de S.; BOLIANI, A.C.; SANTOS, P.C. dos. Enxertia de mesa de Passiflora edulis Sims f. flavicarpa Deg. sobre Passiflora alata Curtis, em ambiente de nebulização intermitente. Revista Brasileira de Fruticultura, Jaboticabal, v.27, n.1, p.98-101, 2005.
STENZEL, N.M.C.; CARVALHO, S.L.C.de. Comportamento do maracujazeiro-amarelo (Passiflora edulis f. flavicarpa Deg.) enxertado sobre diferentes porta-enxertos. Revista Brasileira de Fruticultura, Jaboticabal, v.14, n.3, p.183-186, 1992.

YAMASHIRO, T.; LANDGRAFF, J.H. Maracujáaçu (Passiflora alata Ait), porta-enxerto resistente à fusariose do maracujazeiro (Passiflora edulis $\mathrm{f}$. flavicarpa Deg.). In: CONGRESSO BRASILEIRO DE FRUTICULTURA, 5., 1979, Pelotas. Anais... p.918-921. 